Int. J. Electrochem. Sci., 15 (2020) $434-441$

International Journal of

ELECTROCHEMICAL

SCIENCE

WWW.electrochemsci.org

\title{
Formation of Amorphous Iron Thin Films during Electrodeposition
}

\author{
M. Saitou \\ Department of Mechanical Systems Engineering, University of the Ryukyus, 1 Senbaru Nishihara-cho \\ Okinawa, 903-0213, Japan \\ E-mail: saitou@tec.u-ryukyu.ac.jp
}

doi: $10.20964 / 2020.01 .72$

Received: 3 October 2019 / Accepted: 6 November 2019 / Published: 30 November 2019

In this study, the crystallographic structure transition of iron thin films during electrodeposition (using a rectangular pulse current at a rate of $2 \mathrm{MHz}$ ) was investigated using X-ray diffraction (XRD). The mean grain size estimated by the Scherrer equation reached a minimum value for a specific amplitude and duty cycle of the rectangular pulse current; moreover, the minimum grain size decreased with the deposition temperature. The present XRD analysis demonstrated the deposition of amorphous iron films at temperatures $\leq 295 \mathrm{~K}$ and duty cycles $\geq 40 \%$.

Keywords: Amorphous iron thin film, Rectangular pulse current, Mean grain size, Scherrer equation

\section{FULL TEXT}

(C) 2020 The Authors. Published by ESG (www.electrochemsci.org). This article is an open access article distributed under the terms and conditions of the Creative Commons Attribution license (http://creativecommons.org/licenses/by/4.0/). 